\title{
From hatching to dispatching: the multiple cellular roles of the Hsp70 molecular chaperone machinery
}

\author{
Eirini Meimaridou, Sakina B Gooljar and J Paul Chapple \\ Centre for Endocrinology, William Harvey Research Institute, Barts and the London School of Medicine and Dentistry, London EC1M 6BQ, UK \\ (Correspondence should be addressed to J P Chapple; Email: j.p.chapple@qmul.ac.uk)
}

\begin{abstract}
Molecular chaperones are best recognized for their roles in de novo protein folding and the cellular response to stress. However, many molecular chaperones, and in particular the Hsp70 chaperone machinery, have multiple diverse cellular functions. At the molecular level, chaperones are mediators of protein conformational change. To facilitate conformational change of client/substrate proteins, in manifold contexts, chaperone power must be closely regulated and harnessed to specific cellular locales - this is controlled by cochaperones. This review considers specialized functions of the Hsp70 chaperone machinery mediated by its cochaperones. We focus on vesicular trafficking, protein degradation and a potential role in $\mathrm{G}$ protein-coupled receptor processing.
\end{abstract}

Journal of Molecular Endocrinology (2009) 42, 1-9

\section{Introduction}

To become functional and fulfil their cellular roles, the vast majority of proteins must fold into complex threedimensional shapes. Proteins may not be able to fold fully until their polypeptide chain and/or other subunits are fully synthesized. Partially folded proteins may have undesirable interactions with other essential cellular molecules. Thus, incorrect folding leads to a reduction in levels of functional proteins. Furthermore, additional detrimental effects may be caused by the aggregation of misfolded polypeptides (Dobson 2003). To combat the problems of cellular protein folding helper proteins, which function as 'molecular chaperones', have evolved.

The best recognized role for chaperones in the context of molecular endocrinology is their essential involvement in the functional maturation of steroid receptors, where it has become clear that receptor folding, maturation, nuclear trafficking and disassembly of transcriptional regulatory complexes are all chaperone dependent (Freeman \& Yamamoto 2002, Prescott \& Coetzee 2006, Grad \& Picard 2007). The chaperone system that is responsible for the maturation of steroid receptors, to a conformation that is capable of high-affinity hormone binding, is comprised of Hsc70 (the cytoplasmic cognate Hsp70), Hsp90 and a number of cofactors known as cochaperones (Pratt \& Toft 2003, Prescott \& Coetzee 2006, Grad \& Picard 2007, Smith \& Toft 2008). The paradigm of Hsc70 and
Hsp90 chaperone systems functioning throughout the life cycle of steroid receptors clearly illustrates that chaperones do not function solely in the folding of newly translated proteins, but are required for multiple cellular processes.

In fact, for the Hsc70 chaperone machinery, a very broad range of localized functions have been identified (Young et al. 2003), that go well beyond steroid receptor processing. Here, we give an overview of the Hsp70 molecular chaperone machinery and then describe examples of specialized Hsc70 functions, concentrating on endocytosis, exocytosis and protein degradation. Finally, we also consider whether the Hsp70 machinery may have a role in the processing of $\mathrm{G}$ protein-coupled receptors (GPCRs).

\section{Hsp70 proteins and their cochaperones}

The majority of genomes code for multiple members of the Hsp70 molecular chaperone family, with higher organisms processing more Hsp70s. In humans, there are $13 \mathrm{Hsp} 70$ proteins (whilst there are only three in Escherichia coli), plus four related Hsp110 proteins (Vos et al. 2008). The first Hsp70 proteins to be identified were strongly induced in response to heat shock e.g. Hsp70/HspA1A. These included some family members with high levels of constitutive expression. Further family members have been found in multiple cellular

DOI: 10.1677/JME-08-0116 Online version via http://www.endocrinology-journals.org 
compartments and with tissue specific localizations. These include cytoplasmic (Hsc70/HspA8), endoplasmic reticulum (ER; BiP/Grp78/HspA5) and mitochondrial (mtHsp70/Grp75/HspA9) Hsp70s.

When proteins are not natively folded, hydrophobic amino acids, which are normally buried in the core of folded globular proteins, may be exposed. This may lead to undesirable interactions with peptides, nucleic acids and other macromolecules. Chaperones, including $\mathrm{Hsc} 70$, solve this problem by binding to nascent peptides soon after they exit the ribosome, shielding hydrophobic residues from unproductive interactions (Young et al. 2004, Bukau et al. 2006).

For Hsp70 chaperones (in common with Hsp90 and chaperonins), cycles of client protein binding and release are coupled to conformational change of the chaperone, driven by ATP hydrolysis and exchange (Fig. 1). Chaperone ATPase activity and binding is regulated by the action of cochaperones, some of which have chaperone activity in their own right. Hsc70 is regulated by cochaperones (Table 1) including DnaJ/Hsp40 proteins (subsequently referred to as DnaJ proteins), Bag-family proteins, Hip, Hop and C-terminus of Hsp70 interacting protein (CHIP; Young et al. 2004, Bukau et al. 2006). DnaJ proteins contain a conserved 70 amino acid J-domain that can stimulate the ATPase activity of Hsp70 proteins. Hsc70 binds short regions of peptides with a certain position and pattern of hydrophobic residues. DnaJ proteins play a role in presenting clients to $\mathrm{Hsc} 70$ and when clients are delivered to Hsc70 stabilize binding. This is achieved by switching Hsc70 from an ATP bound state, where client peptide has access to an open substrate-binding pocket, to an ADP bound state where conformational change causes an $\alpha$-helical lid structure to 'clamp' the peptide (Liu \& Hendrickson 2007, Saibil 2008). Interestingly, it has been suggested that clamp-like structural features used to grip substrate proteins are a feature of many chaperone systems (Stirling et al. 2006).

Hsc70 has a flexible interdomain linker connecting a substrate-binding domain (SBD) and a nucleotidebiding domain (NBD). Structural analyses of the interaction between Hsc70 and the J-domain of DnaJC6/auxilin (the cellular function of this DnaJ protein is discussed later in this review) show that the Hsc70 SBD and NBD interact in the ADP-bound state, and that the auxilin J-domain activates $\mathrm{Hsc} 70$ by directing the interdomain linker towards a hydrophobic patch on the NBD surface (Jiang et al. 2007). Thus, the J-domain displaces the SBD from the NBD. It has been suggested that this conformational change may free the SBD to capture client proteins (Jiang et al. 2007). This study indicates some mechanistic differences to the activation of prokaryotic Hsp70, where SBD and NBD do not interact in the ADP-bound state (Swain et al. 2007). Intriguingly, it has been suggested that the equilibrium between conformation states could be set differently in

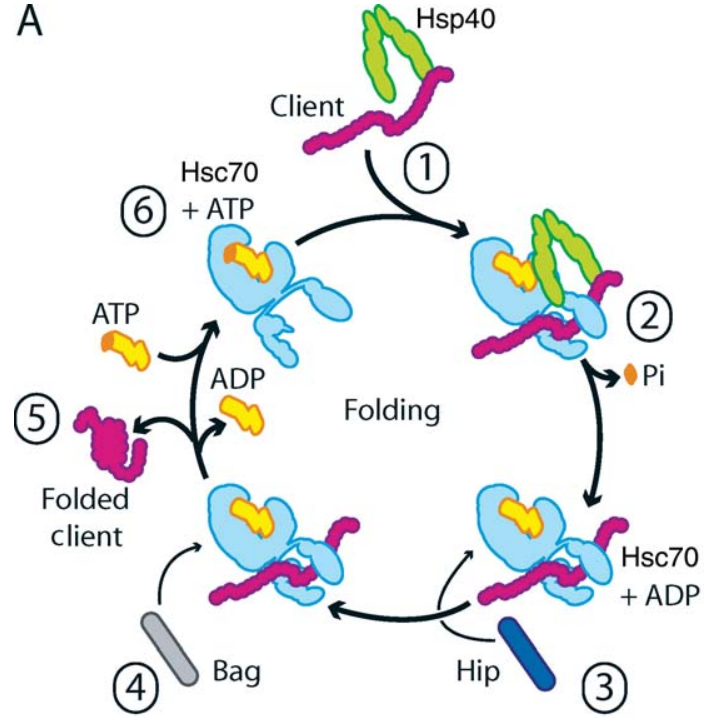

B
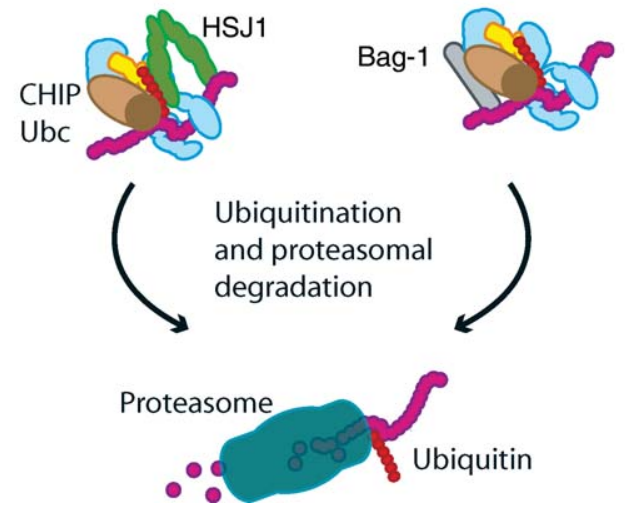

Figure $1 \mathrm{Hsc70}$ and its cochaperones function in both protein folding and degradation. (A) Schematic of the Hsc70 ATPase cycle. For Hsc70 mediated folding cycles of client protein binding and release are coupled to conformational change of the chaperone, driven by ATP hydrolysis and exchange. (1) Hsp40 (shown as a dimer in the schematic) captures nascent or misfolded client proteins and presents them to Hsc70. Other DnaJ proteins can substitute for Hsp40. (2) J-domain stimulates the ATPase activity of Hsc70 resulting in conformational change and 'clamping' of client protein in the substrate-binding pocket. (3) Hip stabilizes the client protein bound ADP state of Hsc70 further promoting folding. (4) Bag protein binding stimulates nucleotide exchange. In humans HspBP1 and Hsp1 10 can also act as Hsc70 nucleotide exchange factors. (5) Client proteins may undergo multiple cycles of Hsc70 binding and release before reaching a natively folded state. (6) ATP-bound Hsc70 is in the 'open' conformation. (B) Hsc70 cochaperone complexes that promote client protein ubiquitination and proteasomal degradation are illustrated. CHIP interacts with Hsc70 via a TPR domain and acts as an ubiquitin ligase for $\mathrm{Hsc70}$ clients, recruiting ubiquitin conjugating enzyme (Ubc) family members through its U-box domain. HSJ1 binds ubiquitin chains on Hsc70 clients via its ubiquitin interaction motifs, protecting them from chain trimming by ubiquitin hydrolases. HSJ1 also presents client to Hsc70 and is also able to stimulate ATPase activity via its J-domain. Bag-1 binds to Hsc70 via its Bag domain and interacts directly with the proteasome via an ubiquitin-like domain (Arndt et al. 2007). 
Table 1 Cochaperones of human Hsc70

\section{Cellular role}

\section{Cochaperone \\ DnaJ/Hsp40 proteins \\ Type I \\ DnaJA1/DJ-2 \\ DnaJA2/Rdj2 \\ DnaJA3/Tid1 \\ DnaJA4/Dj4}

Type II $^{\mathrm{a}}$

DnaJB1/Hsp40

DnaJB2/HSJ1

\author{
DnaJB4/hlj1 \\ DnaJB6/Mrj \\ Type III $^{\mathrm{b}}$ \\ DnaJC5/CSP \\ DnaJC5B/Csp- $\beta$ \\ DnaJC6/Auxilin \\ DnaJC13/Rme8 \\ DnaJC22
}

DnaJC28/GAK

Nucleotide exchange factors

Bag-1 (Bcl-2 associated athanogene 1)

Bag-2 (Bcl-2 associated athanogene 2)

Bag-3 (Bcl-2 associated athanogene 3)

Bag-4 (Bcl-2 associated athanogene 4)

Bag-5 (Bcl-2 associated athanogene 5)

Bag-6 (Bcl-2 associated athanogene 6)

HspBP1 (Hsp70 binding protein 1)

Hsp110

Other Hsc70 cochaperones

Hip (Hsp70 interacting protein)

Hop (Hsp70/Hsp90 organizing protein)

proteins

from DnaJA2 development clients domain
Protein folding

Protein folding has been shown to interact with G Rosales-Hernandez et al. (2008)

Mitochondrial DnaJ protein, however, has been

reported to also interact with cytosolic Hsc70

Protein folding may have different client specificity Hafizur et al. (2004)

Protein folding. Stress inducible. Role in steroid receptor maturation

Contains ubiquitin interaction motifs and promotes Westhoff et al. (2005)

UPS mediated degradation of Hsc70 clients.

Prenylated isoform localizes to cytoplasmic side

of ER membrane and can interact with the GPCR rhodopsin. Highly expressed in neuronal tissues

Housekeeping Hsp40. Reported to bind the

GPCR mu opioid receptor

Binds to keratin and plays a role in placental

Secretory vesicle associated protein involved in regulated exocytosis

Involved in regulated exocytosis

Uncoating of clathrin-coated vesicles

Intracellular trafficking

Human homologue of the Drosophila protein

wurst that functions in endocytosis

Uncoating of clathrin-coated vesicles

Initially identified as an interacting partner of the apoptosis inhibitor Bcl-2. Stimulates nucleotide exchange during the Hsc70 ATPase cycle. Binds to the proteasome via a ubiquitin-like domain and stimulates CHIP mediated degradation of Hsc70

Binds to the ATPase domain of Hsc70 inhibiting chaperone activity. Inhibits CHIP-dependent ubiquitin ligase activity

Inhibits Hsc70 dependent proteasomal degradation. Binds phospholipase $\mathrm{C}-\gamma$

Regulator of cell death dependent on Hsp70

Binds Hsc70. Inhibits the parkin E3 ligase and Hsc70 chaperone activity

Involved in apoptosis and cell proliferation. Interacts with $\mathrm{Hsc70}$ and SGT in prometaphase Nucleotide exchange factor of Hsc70. Binds ATPase domain of Hsc70 competitively with Bag and Hip. Inhibits CHIP E3 ligase activity

Atypical Hsp70 like proteins that act as a nucleotide exchange factors, significantly enhancing Hsc70 ATPase cycle

Stabilizes the ADP client bound state of Hsc70 and stimulates $\mathrm{Hsc} 70$ mediated protein folding. $\mathrm{Hsc70}$ binding via a tetratricopeptide repeat (TPR)

Can bind both Hsc70 and Hsp90 via TPR

domains. Acts as an adaptor protein that couples the Hsp70 and Hsp90 chaperone systems
Ohtsuka \& Hata (2000)

\section{Reference}

Lu et al. (2006)

Michels et al. (1997)

Ancevska-Taneva et al. (2006)

Izawa et al. (2000)

Evans et al. (2003)

Evans et al. (2003)

Jiang et al. (2007)

Zhang et al. (2001a)

Behr et al. (2007)

Greener et al. (2000)

Alberti et al. (2004)

Arndt et al. (2005)

Doong et al. (2000)

Esser et al. (2004)

Kalia et al. (2004)

Winnefeld et al. (2006)

Kabani et al. (2002)

Vos et al. (2008)

Hohfeld et al. (1995)

Onuoha et al. (2008)

(continued) 
Table 1 Continued

\section{Cellular role}

CHIP (C-terminus of Hsp70 interacting protein)

SGT (small glutamine rich tetratricopeptide repeat domain protein)

\author{
Ubiquitin E3 ligase that can bind both $\mathrm{Hsc70}$ and Tateishi et al. (2004) \\ Hsp90. Acts to switch the Hsp70 chaperone \\ machinery from a protein folding to protein \\ degradation role \\ Functions in exocytosis. Cysteine string protein Natochin et al. (2005) \\ binding. TPR protein
}

a Type II DnaJ proteins with unknown function are not included.

${ }^{b}$ There are more than 20 type III DnaJ proteins and only those discussed in this review are listed.

various Hsp70/DnaJ systems, adapting them for specific cellular roles (Jiang et al. 2007).

The diverse functions of Hsc70 rely on cochaperones, and in particular DnaJ proteins, harnessing its ATPdependent ability to perform 'conformational work'. DnaJ proteins are the largest class of Hsp70 cochaperones (Vos et al. 2008), with more than 40 members in humans, compared with six family members in E. coli. However, it is unclear how many of these DnaJ are partners for Hsc70 as opposed to other Hsp70s. Furthermore, some DnaJ proteins are able to stimulate the ATPase activity of more than one Hsp70 (Hennessy et al. 2005). Outside of the J-domain DnaJ proteins are diverse, with motifs that target them to specific client proteins and cellular locales (Cheetham \& Caplan 1998, Kelley 1998, Walsh et al. 2004). Thus, DnaJ proteins deliver the power of the Hsp70 chaperone machinery to multiple cellular functions. DnaJ proteins have been divided into three classes based on possession of domains, in addition to the J-domain, which are conserved with the archetypal E. coli DnaJ. Type I and type II DnaJ proteins have a N-terminal J-domain whilst in type III DnaJ proteins the J-domain may occur anywhere in the protein. Type III DnaJ proteins are highly divergent in size, sequence and structure and tend to serve highly specialized functions (Cheetham \& Caplan 1998).

In some cases, there is functional cooperation between chaperone machines with clients being passed between different chaperone systems. For example, in yeast the de novo folding of WD40 $\beta$-propeller proteins requires engagement of both an $\mathrm{Hsc70}$ and the yeast cytosolic chaperonin complex (CCT; Siegers et al. 2003). Furthermore, Hsc70 and CCT can form a stable complex that has been suggested to serve to deliver unfolded clients from Hsc70 to the client proteinbinding region of CCT (Cuellar et al. 2008).

The interaction between chaperone systems is also regulated by cochaperones. The cochaperone Hop binds Hsc70 and Hsp90 through its tetratricopeptide repeat (TPR) domain, mediating interaction between them (Odunuga et al. 2004). It is also able to modulate the ATPase activity of both chaperones, thus facilitating the transfer of client proteins. It has recently been suggested that for client protein transfer Hop may align the bound client on Hsp70 with the middle domain of Hsp90, which is involved in client protein binding (Onuoha et al. 2008).

\section{Hsc70-mediated endocytosis}

Clathrin-coated vesicles transport proteins from the plasma membrane (PM) to endosomes and between the endosomal and trans-golgi compartment (Rappoport et al. 2004, Benmerah \& Lamaze 2007). They must be uncoated for vesicle fusion and release of their cargo. It is known that Hsc70, with either auxilin (DnaJC6) or cyclin G-associated kinase (GAK/auxilin-2/DnaJC28) catalyses disassembly of clathrin cages (Chappell et al. 1986, Ungewickell et al. 1995, Greener et al. 2000, Umeda et al. 2000, Eisenberg \& Greene 2007). However, the mechanism by which Hsc70 disrupts the clathrin cage remains to be fully resolved. Recently, it has been reported that Hsc70 binds the motif QLMLT at the C-terminus of the clathrin heavy chain after it is recruited by auxilin (Rapoport et al. 2008). Studies where GAK has been depleted support its role in uncoating and suggest further involvement in endocytosis (Lee et al. 2005, 2008). In particular GAK, together with Hsc70, functions in the recruitment of clathrin adapter proteins and the binding of clathrin to the PM and trans-golgi network. Interestingly, in GAK conditional knockout mouse embryonic fibroblasts, adaptor proteins including AP2, epsin, Eps15 and EPs15R have been reported to be mislocalized in clusters at the PM (Lee et al. 2008).

The Drosophila protein wurst (human orthologue, DnaJC22), a six span transmembrane protein with a C-terminal cytoplasmic J-domain, has also been implicated in endocytosis (Behr et al. 2007). Mutations in wurst cause an increase in Drosophila respiratory tube length due to defective extracellular matrix organization in the tracheal tubes. The wurst J-domain has been shown to interact with fly Hsc70 and to contain a functional clathrin-binding motif. Wurst mutation or knockdown resulted in a reduction in endocytosis and an 
accumulation of clathrin at the PM. The apical PM of tracheal cells from wurst mutant Drosophila is disorganized and appears to contain additional membrane (Behr et al. 2007). Behr et al. (2007) suggest a model where wurst recruits $\mathrm{Hsc} 70$ and clathrin to the apical PM to coordinate the early stages of clathrin-mediated endocytosis.

Additional roles for Hsc70 in intracellular trafficking have recently been identified. The DnaJ protein RME8/DnaJC13 (receptor mediated endocytosis 8 ) was first identified in a screen for endocytic defects in Caenorhabditis elegans (Zhang et al. 2001a). RME-8 has subsequently been co-localized with endosomal markers (Girard $e t$ al. 2005). Fujibayashi et al. (2008) showed that human RME8 co-localizes with early endosome markers and was not associated with late endosomes. Knockdown of RME-8 did not affect cellular levels of receptors that primarily recycle to the PM after clathrin-mediated endocytosis, for example transferrin receptor and insulin receptor. However, RME-8 knockdown has been shown to decrease cellular levels of epidermal growth factor receptor (EGFR) by increasing its degradation, possibly by altering levels of EGFR that are targeted from early endosomes to late endosomes/lysosomes (Girard \& McPherson 2008). RME-8 knockdown has also been reported to alter trafficking of cation-dependent mannose 6-phosphate receptor and cause improper sorting of cathepsin D (Girard et al. 2005).

\section{Hsc70 in exocytosis}

There is strong evidence for Hsc70 playing a role in exocytosis, mediated by the J-domain containing, cysteine string proteins (CSP/DnaJC5; Evans et al. 2003). CSP associates with secretory vesicles, including synaptic vesicles, chromaffin granules, pancreatic zymogen granules, insulin-containing granules and mucin granules (Mastrogiacomo et al. 1994, Braun \& Scheller 1995, Chamberlain et al. 1996, Brown et al. 1998, Park et al. 2008). CSP $\alpha$ knockout mice develop normally, but then undergo severe neurodegeneration starting 2-4 weeks after birth (Fernandez-Chacon et al. 2004). Interestingly, this neurodegeneration phenotype was observed at photoreceptor synapses where $\operatorname{CSP} \alpha$ is expressed in wild-type mice, but not in ribbon synapses of auditory hair cells that contain another CSP isoform (Schmitz et al. 2006). CSP was initially shown to function in the calciumdependent exocytosis of synaptic vesicles when it was reported that in CSP Drosophila mutants $\mathrm{Ca}^{2+}$-dependent neurotransmission is impaired (Umbach et al. 1994). Interestingly, a similar phenotype was observed in flies with Hsc70 mutations (Bronk et al. 2001). It has since been suggested that CSP is an organizer of proteinprotein interactions at different stages of the secretory vesicle cycle, stabilizing exocytotic proteins and their complexes (Evans et al. 2003). Indeed, CSP has been shown to bind soluble $N$-ethylmaleimide sensitive factor attachment protein receptor (SNARE) proteins, which are components of the core membrane fusion machinery. Specifically, CSP has been detected in a complex with syntaxin by immunoprecipitation and has been shown to suppress a syntaxin overexpression phenotype in Drosophila (Nie et al. 1999, Wu et al. 1999). CSP has also been immunoprecipitated with vesicle associated membrane protein, although the interaction with this SNARE is not direct (Leveque et al. 1998). Functions for CSP at several different stages of exocytosis have been identified. These include a role for CSP in GABA uptake into synaptic vesicles, based on data demonstrating, that with Hsc70, it is in a complex with the glutamate decarboxylase (GAD, that catalyses the decarboxylation of glutamate to GABA), the vesicular GABA transporter and the $\mathrm{Ca}^{2+}$-calmodulin-dependent kinase (CaMKII; Hsu et al. 2000, Jin et al. 2003). CSP and Hsc70 have also been identified in a complex with the $\alpha$-GDP-dissociation inhibitor ( $\alpha \mathrm{GDI}$ ) where Hsp90 is also present. $\alpha \mathrm{GDI}$ regulates the cycling of Rab3a, one of a number of Rabs involved in the targeting and docking of vesicles. Interestingly, Hsp90 inhibitors have been shown to block Rab3a cycling (Sakisaka et al. 2002). Another cochaperone has been identified in a trimeric complex with CSP and Hsc70. This protein, small glutamine-rich TPR protein (SGT), is able to bind Hsc70 through its TPR domain and CSP through its N-terminus. SGT overexpression in cultured neurons inhibits neurotransmitter release (Tobaben et al. 2001). There is also evidence that CSP may associate with N-type $\mathrm{Ca}^{2+}$. channels via heterotrimeric GTP-binding proteins (G proteins). CSP $\alpha$ has been shown to bind $G$ protein subunits and stimulate GDP/GTP exchange of $\mathrm{G} \alpha_{\mathrm{s}}$, dependent on Hsc70 and SGT (Natochin et al. 2005).

\section{Molecular chaperones as regulators of protein degradation}

Cells utilize a variety of pathways for the degradation of proteins both during normal protein turnover and as part of their response to proteins that become damaged by environmental stress or are mutated. Cytosolic, nuclear and ER proteins are primarily degraded by the ubiquitin-proteasome system (UPS), however, most cells also rely on lysosomal proteolysis pathways, particularly under nutrient-limiting conditions (Majeski \& Dice 2004). The Hsc70 chaperone machinery plays a role in the targeting of client proteins to both of these systems.

Hsc70 is linked to the UPS by its cochaperones (Fig. 1) and in particular CHIP. CHIP negatively regulates Hsc70 chaperone activity and acts as an E3 ubiquitin ligase for Hsc70 client proteins. In vitro CHIP has been shown to target a number of proteins for degradation including oestrogen receptor- $\alpha$ (in its non ligand bound state; 
Tateishi et al. 2004) and the cystic fibrosis transmembrane conductance regulator (CFTR). Several other Hsc70 cochaperones also interact with the UPS. These include Bag-1 that acts as a nucleotide exchange factor for Hsc70 (causing client protein release) and contains an ubiquitin-like domain through which it interacts with the proteasome, stimulating CHIP mediated degradation of Hsc70 clients (Alberti et al. 2003) including the glucocorticoid hormone receptor (Demand et al. 2001). HSJ1b also promotes the degradation of Hsp70 clients as it contains two ubiquitin interaction motifs, through which it binds ubiquitinated proteins, shielding ubiquitin chains from the action of chain trimming ubiquitin hydrolases and facilitating sorting of ubiquitinated Hsp70 clients to the proteasome (Westhoff et al. 2005). The Hsc70 cochaperones HspBP1, Bag-2 and Bag-5 have an opposing effect to Bag-1 and HSJ1, acting as inhibitors of chaperone-mediated degradation (Esser et al. 2004). For example, HspBP1 and Bag-2 have been shown to inhibit CHIP mediated degradation of CFTR (Alberti et al. 2004, Arndt et al. 2005). Thus, the targeting of client proteins from the Hsc70 chaperone machine to the UPS is closely regulated by cochaperones.

Membrane proteins and luminal proteins retrotranslocated from the ER are also targeted for degradation by the UPS by a process called ER-associated degradation (ERAD). Again cytosolic chaperones play a role, for example in yeast a cytosolic Hsp70, Ssa1p, has been shown to be required for ERAD of membrane proteins including CFTR (Zhang et al. 2001b). It has been suggested Ssalp maintains the solubility of misfolded cytoplasmic membrane protein domains, facilitating targeting to the UPS (Nishikawa et al. 2005).

The lysosomal proteolysis pathway of chaperonemediated autophagy (CMA) also relies on $\mathrm{Hsc} 70$ and its cochaperones (Majeski \& Dice 2004). CMA differs from other lysosomal degradation pathways in that it is independent of vesicular transport. In CMA client proteins, which contain a KFERQ like motif, are recognized by an Hsc70/Hsp90 chaperone complex that includes the cochaperones Hsp40/DnaJB1, Hip, Hop and Bag-1. This complex then binds with the lysosomal membrane receptor Lamp2a via the client protein. The chaperone complex is likely to unfold client proteins for import into the lysosome (Salvador et al. 2000). Fascinatingly, Hsc70 contains two KFERQ sequences and is found in the lumen of CMA lysosomes where it further functions in protein import. However, lysosomes do not contain ATP, suggesting ly-Hsc70 utilizes a different mechanism for the import of proteins into the lysosomal lumen than for other organelle Hsp70s (e.g. BiP in the ER lumen). It has been suggested CMA may be able to degrade up to $30 \%$ of cytosolic proteins under conditions of prolonged nutrient deprivation (Dice 2007). CMA has also recently been shown to be activated by oxidative stress coupled to an increase in Hsc70 in the lysosomal lumen and Lamp2a in the lysosomal membrane (Kiffin et al. 2004).

\section{A role for Hsp70 proteins in GPCR trafficking?}

The human genome encodes $\sim 450$ GPCR proteins with endogenous ligands (plus a further 500 odorant receptors). These receptors are particularly relevant to human health as they represent the target for $\sim 30 \%$ of marketed drugs. For GPCRs to transmit extracellular signals into the cell they must be trafficked to the cell surface. The processing of some GPCRs has been shown to be influenced by specific accessory proteins (Tan et al. 2004, Clark et al. 2005). There is evidence that many of these GPCR-interactors have a molecular chaperone function. For example, in Drosophila, a cyclophilin homologue, Nina A, with peptidyl-prolyl isomerase activity is essential for rhodopsin Rh1 expression (Stamnes et al. 1991, Baker et al. 1994). In addition to specific accessory proteins/interacting partners facilitating GPCR processing, more ubiquitous components of the cellular molecular chaperone machinery can modulate their folding, trafficking and degradation. Hsp70 proteins have been suggested to promote the processing of both wild-type and mutant GPCRs to the PM. For example, the testis enriched Hsp70 variant, Hsc70t/HspA1L, enhances the expression and trafficking to the cell surface of odorant receptors (Neuhaus et al. 2006); whilst Hsc70 has been demonstrated to interact with cytoplasmic domains of non-glycosylated angiotensin II type 1 receptor (Lanctot et al. 2006). Furthermore, in cultured cells, the Hsp70 cochaperone HSJ1b can modulate the processing of the archetypal GPCR rhodopsin. HSJ1b interacts with rhodopsin and prevents the protein transiting from the ER to the Golgi and on to the PM (Chapple \& Cheetham 2003). Another DnaJ protein, hlj1/DnaJB4 has been shown to interact with the human mu opioid receptor via binding its C-terminal domain (Ancevska-Taneva et al. 2006). Interestingly, hlj1 has tumour suppressor activity (Tsai et al. 2006).

As the majority of hormones signal through GPCRs, many of the diseases associated with mutations in GPCRs disrupt endocrine systems. These included nephrogenic diabetes insipidus caused by mutations in the vasopressin type 2 receptor, familial glucocorticoid deficiency caused by mutations in the melanocortin 2 receptor, and obesity caused by mutations in the melanocortin 4 receptor. In human diseases, where GPCRs are mutated it is common for the receptor to fail to traffic to the cell surface (Conn et al. 2007). A failure to transit from the ER to the PM occurs because mutated proteins, including GPCRs, are detected as 'misfolded' by the ER quality control system 
(Conn et al. 2007, Anelli \& Sitia 2008). ER resident chaperones (e.g. BiP) play a major role in regulating this quality control, recognizing aberrantly folded protein, preventing their routing to the Golgi and subsequently targeting them for ERAD. The apparent role of the cytosolic Hsp70 machinery in GPCR processing could suggest these chaperones are also involved in determining the fate of misfolded transmembrane proteins. Both ER and cytosolic Hsp70 chaperone networks represent potential sites for therapeutic intervention in diseases where GPCRs fail to transit to the PM.

\section{Conclusions}

Hsc70 is a chaperone multi-tool with involvement in a still expanding list of cellular pathways. This versatility is achieved through Hsc70's cochaperones and in particular DnaJ proteins. Although Hsc70 is a cytoplasmic protein it can be recruited to intracellular membranes by membrane associated cochaperones, such as the prenylated DnaJ proteins HSJ1b (Chapple \& Cheetham 2003), and the cytoskeleton. For example the DnaJ protein Mrj connects Hsc70 with intermediate filaments, where it may be involved in their regulated assembly (Izawa et al. 2000). Interestingly, the fact that Hsc70 is closely linked to endocytosis, vesicular trafficking and exocytosis suggests it may be involved in the regulation of multiple cellular signalling pathways, in addition to those mediated by nuclear steroid receptors.

For GPCRs endocytosis can control signal termination, propagation and resensitization (Wolfe \& Trejo 2007, Hanyaloglu \& von Zastrow 2008). Also both Hsp70 proteins and DnaJ proteins have been shown to directly interact with GPCRs modulating their processing, whilst CSP binds $G$ protein subunits. Furthermore, another DnaJ protein, Rdj2 (DnaJA2), has recently been shown to interact with $\mathrm{G}$ proteins and can modulate $\mathrm{G}$ protein signalling (Rosales-Hernandez et al. 2008).

\section{Declaration of interest}

The authors declare that there is no conflict of interest that could be perceived as prejudicing the impartiality of the research reported.

\section{Funding}

E M is supported by Barts and the London Charity.

\section{References}

Alberti S, Esser C \& Hohfeld J 2003 BAG-1 - a nucleotide exchange factor of Hsc70 with multiple cellular functions. Cell Stress and Chaperones 8 225-231.
Alberti S, Bohse K, Arndt V, Schmitz A \& Hohfeld J 2004 The cochaperone HspBP1 inhibits the CHIP ubiquitin ligase and stimulates the maturation of the cystic fibrosis transmembrane conductance regulator. Molecular Biology of the Cell 15 4003-4010.

Ancevska-Taneva N, Onoprishvili I, Andria ML, Hiller JM \& Simon EJ 2006 A member of the heat shock protein 40 family, hlj1, binds to the carboxyl tail of the human mu opioid receptor. Brain Research 1081 28-33.

Anelli T \& Sitia R 2008 Protein quality control in the early secretory pathway. EMBO Journal 27 315-327.

Arndt V, Daniel C, Nastainczyk W, Alberti S \& Hohfeld J 2005 BAG-2 acts as an inhibitor of the chaperone-associated ubiquitin ligase CHIP. Molecular Biology of the Cell 16 5891-5900.

Arndt V, Rogon C \& Hohfeld J 2007 To be or not to be - molecular chaperones in protein degradation. Cellular and Molecular Life Sciences 64 2525-2541.

Baker EK, Colley NJ \& Zuker CS 1994 The cyclophilin homolog NinaA functions as a chaperone, forming a stable complex in vivo with its protein target rhodopsin. EMBO Journal 13 4886-4895.

Behr M, Wingen C, Wolf C, Schuh R \& Hoch M 2007 Wurst is essential for airway clearance and respiratory-tube size control. Nature Cell Biology 9 847-853.

Benmerah A \& Lamaze C 2007 Clathrin-coated pits: vive la difference? Traffic 8 970-982.

Braun JE \& Scheller RH 1995 Cysteine string protein, a DnaJ family member, is present on diverse secretory vesicles. Neuropharmacology 34 1361-1369.

Bronk P, Wenniger JJ, Dawson-Scully K, Guo X, Hong S, Atwood HL \& Zinsmaier KE 2001 Drosophila Hsc70-4 is critical for neurotransmitter exocytosis in vivo. Neuron 30 475-488.

Brown H, Larsson O, Branstrom R, Yang SN, Leibiger B, Leibiger I, Fried G, Moede T, Deeney JT, Brown GR et al. 1998 Cysteine string protein (CSP) is an insulin secretory granule-associated protein regulating beta-cell exocytosis. EMBO Journal 17 $5048-5058$.

Bukau B, Weissman J \& Horwich A 2006 Molecular chaperones and protein quality control. Cell 125 443-451.

Chamberlain LH, Henry J \& Burgoyne RD 1996 Cysteine string proteins are associated with chromaffin granules. Journal of Biological Chemistry 271 19514-19517.

Chappell TG, Welch WJ, Schlossman DM, Palter KB, Schlesinger MJ \& Rothman JE 1986 Uncoating ATPase is a member of the 70 kilodalton family of stress proteins. Cell 45 3-13.

Chapple JP \& Cheetham ME 2003 The chaperone environment at the cytoplasmic face of the endoplasmic reticulum can modulate rhodopsin processing and inclusion formation. Journal of Biological Chemistry 278 19087-19094.

Cheetham ME \& Caplan AJ 1998 Structure, function and evolution of DnaJ: conservation and adaptation of chaperone function. Cell Stress and Chaperones 3 28-36.

Clark AJ, Metherell LA, Cheetham ME \& Huebner A 2005 Inherited ACTH insensitivity illuminates the mechanisms of ACTH action. Trends in Endocrinology and Metabolism 16 451-457.

Conn PM, Ulloa-Aguirre A, Ito J \& Janovick JA 2007 G protein-coupled receptor trafficking in health and disease: lessons learned to prepare for therapeutic mutant rescue in vivo. Pharmacological Reviews 59 225-250.

Cuellar J, Martin-Benito J, Scheres SH, Sousa R, Moro F, Lopez-Vinas E, Gomez-Puertas P, Muga A, Carrascosa JL \& Valpuesta JM 2008 The structure of CCT-Hsc70 NBD suggests a mechanism for Hsp70 delivery of substrates to the chaperonin. Nature Structural and Molecular Biology 15 858-864.

Demand J, Alberti S, Patterson C \& Hohfeld J 2001 Cooperation of a ubiquitin domain protein and an E3 ubiquitin ligase during chaperone/proteasome coupling. Current Biology 11 1569-1577. Dice JF 2007 Chaperone-mediated autophagy. Autophagy 3 295-299. Dobson CM 2003 Protein folding and misfolding. Nature 426 884-890. 
Doong H, Price J, Kim YS, Gasbarre C, Probst J, Liotta LA, Blanchette J, Rizzo K \& Kohn E 2000 CAIR-1/BAG-3 forms an EGF-regulated ternary complex with phospholipase C-gamma and Hsp70/Hsc70. Oncogene 19 4385-4395.

Eisenberg E \& Greene LE 2007 Multiple roles of auxilin and hsc70 in clathrin-mediated endocytosis. Traffic 8 640-646.

Esser C, Alberti S \& Hohfeld J 2004 Cooperation of molecular chaperones with the ubiquitin/proteasome system. Biochimica et Biophysica Acta 1695 171-188.

Evans GJ, Morgan A \& Burgoyne RD 2003 Tying everything together: the multiple roles of cysteine string protein (CSP) in regulated exocytosis. Traffic 4 653-659.

Fernandez-Chacon R, Wolfel M, Nishimune H, Tabares L, Schmitz F, Castellano-Munoz M, Rosenmund C, Montesinos ML, Sanes JR, Schneggenburger R et al. 2004 The synaptic vesicle protein CSP alpha prevents presynaptic degeneration. Neuron 42 237-251.

Freeman BC \& Yamamoto KR 2002 Disassembly of transcriptional regulatory complexes by molecular chaperones. Science 296 2232-2235.

Fujibayashi A, Taguchi T, Misaki R, Ohtani M, Dohmae N, Takio K, Yamada M, Gu J, Yamakami M, Fukuda M et al. 2008 Human RME-8 is involved in membrane trafficking through early endosomes. Cell Structure and Function 33 35-50.

Girard M \& McPherson PS 2008 RME-8 regulates trafficking of the epidermal growth factor receptor. FEBS Letters 582 961-966.

Girard M, Poupon V, Blondeau F \& McPherson PS 2005 The DnaJdomain protein RME-8 functions in endosomal trafficking. Journal of Biological Chemistry 280 40135-40143.

Grad W \& Picard D 2007 The glucocorticoid responses are shaped by molecular chaperones. Molecular and Cellular Endocrinology 275 2-12.

Greener T, Zhao X, Nojima H, Eisenberg E \& Greene LE 2000 Role of cyclin G-associated kinase in uncoating clathrin-coated vesicles from non-neuronal cells. Journal of Biological Chemistry 275 1365-1370.

Hafizur RM, Yano M, Gotoh T, Mori M \& Terada K 2004 Modulation of chaperone activities of Hsp70 and Hsp70-2 by a mammalian DnaJ/Hsp40 homolog, DjA4. Journal of Biochemistry 135 193-200.

Hanyaloglu AC \& von Zastrow M 2008 Regulation of GPCRs by endocytic membrane trafficking and its potential implications. Annual Review of Pharmacology and Toxicology 48 537-568.

Hennessy F, Nicoll WS, Zimmermann R, Cheetham ME \& Blatch GL 2005 Not all J domains are created equal: implications for the specificity of Hsp40-Hsp70 interactions. Protein Science 14 1697-1709.

Hohfeld J, Minami Y \& Hartl FU 1995 Hip, a novel cochaperone involved in the eukaryotic Hsc70/Hsp40 reaction cycle. Cell 83 589-598.

Hsu CC, Davis KM, Jin H, Foos T, Floor E, Chen W, Tyburski JB, Yang CY, Schloss JV \& Wu JY 2000 Association of L-glutamic acid decarboxylase to the $70-\mathrm{kDa}$ heat shock protein as a potential anchoring mechanism to synaptic vesicles. Journal of Biological Chemistry 275 20822-20828.

Izawa I, Nishizawa M, Ohtakara K, Ohtsuka K, Inada H \& Inagaki M 2000 Identification of Mrj, a DnaJ/Hsp40 family protein, as a keratin 8/18 filament regulatory protein. Journal of Biological Chemistry 275 34521-34527.

Jiang J, Maes EG, Taylor AB, Wang L, Hinck AP, Lafer EM \& Sousa R 2007 Structural basis of J cochaperone binding and regulation of Hsp70. Molecular Cell 28 422-433.

Jin H, Wu H, Osterhaus G, Wei J, Davis K, Sha D, Floor E, Hsu CC, Kopke RD \& Wu JY 2003 Demonstration of functional coupling between gamma-aminobutyric acid (GABA) synthesis and vesicular GABA transport into synaptic vesicles. PNAS 100 4293-4298.

Kabani M, McLellan C, Raynes DA, Guerriero V \& Brodsky JL 2002 HspBP1, a homologue of the yeast Fes1 and Sls1 proteins, is an Hsc70 nucleotide exchange factor. FEBS Letters 531 339-342.

Kalia SK, Lee S, Smith PD, Liu L, Crocker SJ, Thorarinsdottir TE, Glover JR, Fon EA, Park DS \& Lozano AM 2004 BAG5 inhibits parkin and enhances dopaminergic neuron degeneration. Neuron 44 931-945.

Kelley WL 1998 The J-domain family and the recruitment of chaperone power. Trends in Biochemical Sciences 23 222-227.
Kiffin R, Christian C, Knecht E \& Cuervo AM 2004 Activation of chaperone-mediated autophagy during oxidative stress. Molecular Biology of the Cell 15 4829-4840.

Lanctot PM, Leclerc PC, Escher E, Guillemette G \& Leduc R 2006 Role of $\mathrm{N}$-glycan-dependent quality control in the cell-surface expression of the AT1 receptor. Biochemical and Biophysical Research Communications 340 395-402.

Lee DW, Zhao X, Zhang F, Eisenberg E \& Greene LE 2005 Depletion of GAK/auxilin 2 inhibits receptor-mediated endocytosis and recruitment of both clathrin and clathrin adaptors. Journal of Cell Science 118 4311-4321.

Lee DW, Zhao X, Yim YI, Eisenberg E \& Greene LE 2008 Essential role of cyclin-G-associated kinase (Auxilin-2) in developing and mature mice. Molecular Biology of the Cell 19 2766-2776.

Leveque C, Pupier S, Marqueze B, Geslin L, Kataoka M, Takahashi M, De Waard M \& Seagar M 1998 Interaction of cysteine string proteins with the alphalA subunit of the P/Q-type calcium channel. Journal of Biological Chemistry 273 13488-13492.

Liu Q \& Hendrickson WA 2007 Insights into Hsp70 chaperone activity from a crystal structure of the yeast Hsp110 Sse1. Cell 131 106-120.

Lu B, Garrido N, Spelbrink JN \& Suzuki CK 2006 Tid1 isoforms are mitochondrial DnaJ-like chaperones with unique carboxyl termini that determine cytosolic fate. Journal of Biological Chemistry 281 13150-13158.

Majeski AE \& Dice JF 2004 Mechanisms of chaperone-mediated autophagy. International Journal of Biochemistry and Cell Biology 36 2435-2444.

Mastrogiacomo A, Parsons SM, Zampighi GA, Jenden DJ, Umbach JA \& Gundersen CB 1994 Cysteine string proteins: a potential link between synaptic vesicles and presynaptic $\mathrm{Ca}^{2+}$ channels. Science 263 981-982.

Michels AA, Kanon B, Konings AW, Ohtsuka K, Bensaude O \& Kampinga HH 1997 Hsp70 and Hsp40 chaperone activities in the cytoplasm and the nucleus of mammalian cells. Journal of Biological Chemistry 272 33283-33289.

Natochin M, Campbell TN, Barren B, Miller LC, Hameed S, Artemyev NO \& Braun JE 2005 Characterization of the $\mathrm{G}$ alpha(s) regulator cysteine string protein. Journal of Biological Chemistry 280 30236-30241.

Neuhaus EM, Mashukova A, Zhang W, Barbour J \& Hatt H 2006 A specific heat shock protein enhances the expression of mammalian olfactory receptor proteins. Chemical Senses 31 445-452.

Nie Z, Ranjan R, Wenniger JJ, Hong SN, Bronk P \& Zinsmaier KE 1999 Overexpression of cysteine-string proteins in Drosophila reveals interactions with syntaxin. Journal of Neuroscience 19 10270-10279.

Nishikawa S, Brodsky JL \& Nakatsukasa K 2005 Roles of molecular chaperones in endoplasmic reticulum (ER) quality control and ER-associated degradation (ERAD). Journal of Biochemistry 137 $551-555$.

Odunuga OO, Longshaw VM \& Blatch GL 2004 Hop: more than an Hsp70/Hsp90 adaptor protein. BioEssays 26 1058-1068.

Ohtsuka K \& Hata M 2000 Mammalian HSP40/DNAJ homologs: cloning of novel cDNAs and a proposal for their classification and nomenclature. Cell Stress and Chaperones 5 98-112.

Onuoha SC, Coulstock ET, Grossmann JG \& Jackson SE 2008 Structural studies on the co-chaperone Hop and its complexes with Hsp90. Journal of Molecular Biology 379 732-744.

Park J, Fang S, Crews AL, Lin KW \& Adler KB 2008 MARCKS regulation of mucin secretion by airway epithelium in vitro: interaction with chaperones. American Journal of Respiratory Cell and Molecular Biology 39 68-76.

Pratt WB \& Toft DO 2003 Regulation of signaling protein function and trafficking by the hsp90/hsp70-based chaperone machinery. Experimental Biology and Medicine 228 111-133.

Prescott J \& Coetzee GA 2006 Molecular chaperones throughout the life cycle of the androgen receptor. Cancer Letters 231 12-19.

Rapoport I, Boll W, Yu A, Bocking T \& Kirchhausen T 2008 A motif in the clathrin heavy chain required for the hsc70/auxilin uncoating reaction. Molecular Biology of the Cell 19 405-413. 
Rappoport JZ, Simon SM \& Benmerah A 2004 Understanding living clathrin-coated pits. Traffic 5 327-337.

Rosales-Hernandez A, Beck KE, Zhao X, Braun AP \& Braun JE 2008 RDJ2 (DNAJA2) chaperones neural G protein signaling pathways. Cell Stress and Chaperones In Press.

Saibil HR 2008 Chaperone machines in action. Current Opinion in Structural Biology 18 35-42.

Sakisaka T, Meerlo T, Matteson J, Plutner H \& Balch WE 2002 Rab-alphaGDI activity is regulated by a Hsp90 chaperone complex. EMBO Journal 21 6125-6135.

Salvador N, Aguado C, Horst M \& Knecht E 2000 Import of a cytosolic protein into lysosomes by chaperone-mediated autophagy depends on its folding state. Journal of Biological Chemistry 275 27447-27456.

Schmitz F, Tabares L, Khimich D, Strenzke N, de la Villa-Polo P, Castellano-Munoz M, Bulankina A, Moser T, Fernandez-Chacon R \& Sudhof TC 2006 CSPalpha-deficiency causes massive and rapid photoreceptor degeneration. PNAS 103 2926-2931.

Siegers K, Bolter B, Schwarz JP, Bottcher UM, Guha S \& Hartl FU 2003 TRiC/CCT cooperates with different upstream chaperones in the folding of distinct protein classes. EMBO Journal 22 5230-5240.

Smith DF \& Toft DO 2008 The intersection of steroid receptors with molecular chaperones: observations and questions. Molecular Endocrinology In Press.

Stamnes MA, Shieh BH, Chuman L, Harris GL \& Zuker CS 1991 The cyclophilin homolog ninaA is a tissue-specific integral membrane protein required for the proper synthesis of a subset of Drosophila rhodopsins. Cell 65 219-227.

Stirling PC, Bakhoum SF, Feigl AB \& Leroux MR 2006 Convergent evolution of clamp-like binding sites in diverse chaperones. Nature Structural and Molecular Biology 13 865-870.

Swain JF, Dinler G, Sivendran R, Montgomery DL, Stotz M \& Gierasch LM 2007 Hsp70 chaperone ligands control domain association via an allosteric mechanism mediated by the interdomain linker. Molecular Cell 26 27-39.

Tan CM, Brady AE, Nickols HH, Wang Q \& Limbird LE 2004 Membrane trafficking of $\mathrm{G}$ protein-coupled receptors. Annual Review of Pharmacology and Toxicology 44 559-609.

Tateishi Y, Kawabe Y, Chiba T, Murata S, Ichikawa K, Murayama A, Tanaka K, Baba T, Kato S \& Yanagisawa J 2004 Ligand-dependent switching of ubiquitin-proteasome pathways for estrogen receptor. EMBO Journal 23 4813-4823.

Tobaben S, Thakur P, Fernandez-Chacon R, Sudhof TC, Rettig J \& Stahl B 2001 A trimeric protein complex functions as a synaptic chaperone machine. Neuron 31 987-999.

Tsai MF, Wang CC, Chang GC, Chen CY, Chen HY, Cheng CL, Yang YP, Wu CY, Shih FY, Liu CC et al. 2006 A new tumor suppressor DnaJ-like heat shock protein, HLJ1, and survival of patients with non-small-cel lung carcinoma. Journal of the National Cancer Institute 98 825-838.
Umbach JA, Zinsmaier KE, Eberle KK, Buchner E, Benzer S \& Gundersen CB 1994 Presynaptic dysfunction in Drosophila csp mutants. Neuron 13 899-907.

Umeda A, Meyerholz A \& Ungewickell E 2000 Identification of the universal cofactor (auxilin 2) in clathrin coat dissociation. European Journal of Cell Biology 79 336-342.

Ungewickell E, Ungewickell H, Holstein SE, Lindner R, Prasad K, Barouch W, Martin B, Greene LE \& Eisenberg E 1995 Role of auxilin in uncoating clathrin-coated vesicles. Nature 378 632-635.

Vos MJ, Hageman J, Carra S \& Kampinga HH 2008 Structural and functional diversities between members of the human HSPB, HSPH, HSPA, and DNAJ chaperone families. Biochemistry 47 7001-7011.

Walsh P, Bursac D, Law YC, Cyr D \& Lithgow T 2004 The J-protein family: modulating protein assembly, disassembly and translocation. EMBO Reports 5 567-571.

Westhoff B, Chapple JP, van der Spuy J, Hohfeld J \& Cheetham ME 2005 HSJ1 is a neuronal shuttling factor for the sorting of chaperone clients to the proteasome. Current Biology 15 1058-1064.

Winnefeld M, Grewenig A, Schnolzer M, Spring H, Knoch TA, Gan EC, Rommelaere J \& Cziepluch C 2006 Human SGT interacts with Bag$6 /$ Bat-3/Scythe and cells with reduced levels of either protein display persistence of few misaligned chromosomes and mitotic arrest. Experimental Cell Research 312 2500-2514.

Wolfe BL \& Trejo J 2007 Clathrin-dependent mechanisms of G protein-coupled receptor endocytosis. Traffic $8462-470$.

Wu MN, Fergestad T, Lloyd TE, He Y, Broadie K \& Bellen HJ 1999 Syntaxin 1A interacts with multiple exocytic proteins to regulate neurotransmitter release in vivo. Neuron 23 593-605.

Young JC, Barral JM \& Ulrich Hartl F 2003 More than folding: localized functions of cytosolic chaperones. Trends in Biochemical Sciences 28 541-547.

Young JC, Agashe VR, Siegers K \& Hartl FU 2004 Pathways of chaperone-mediated protein folding in the cytosol. Nature Reviews. Molecular Cell Biology 5 781-791.

Zhang Y, Grant B \& Hirsh D 2001 $a$ RME-8, a conserved J-domain protein, is required for endocytosis in Caenorhabditis elegans. Molecular Biology of the Cell 12 2011-2021.

Zhang Y, Nijbroek G, Sullivan ML, McCracken AA, Watkins SC, Michaelis S \& Brodsky JL 2001b Hsp70 molecular chaperone facilitates endoplasmic reticulum-associated protein degradation of cystic fibrosis transmembrane conductance regulator in yeast. Molecular Biology of the Cell 12 1303-1314.

Received in final form 8 October 2008

Accepted 13 October 2008

Made available online as an Accepted Preprint 13 October 2008 